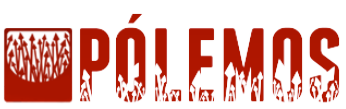

\section{O Hegel de Honneth}

\author{
Filipe Campello ${ }^{1}$ \\ Professor Adjunto de Filosofia \\ Universidade Federal de Pernambuco
}

Resumo: O presente artigo tem como objetivo reconstruir os principais aspectos da interpretação de Hegel proposta por Axel Honneth. Com esse intuito, após expor a recepção da filosofia hegeliana para a elaboração da teoria do reconhecimento de Honneth em sua principal obra - Luta por reconhecimento - (1), discuto como Honneth leva a cabo seu projeto de atualização da teoria hegeliana da eticidade a partir da releitura de sua Filosofia do Direito (2). Numa terceira parte, será apresentada a interpretação de Honneth em torno de possíveis problemas do projeto original de Hegel (3). Ainda que brevemente, concluo sugerindo que, no marco de projeto honnethiano de atualização do pensamento de Hegel, deixa-se entrever a possibilidade de releitura de três conceitos controversos do referencial teórico hegeliano: espírito, teleologia e lógica. Desse modo, tentarei explicitar novos nexos interpretativos em torno da ideia original de Hegel, relida a partir de atuais padrões conceituais, ao tempo em que são apontadas possibilidades de ampliação do projeto de Honneth.

Palavras-chave: Reconhecimento, Eticidade, Filosofia do Direito, Liberdade, Hegel, Honneth

\begin{abstract}
This paper aims to reconstruct the main aspects of the interpretation of Hegel as proposed by Axel Honneth. In this sense, after exposing the reception of the Hegelian philosophy for the elaboration of Honneth's theory of recognition in his main work Struggle for recognition - (1), I discuss how Honneth tries to update theHegelian theory of ethical life through a review of his Philosophy of Right (2). In a third part, it is shown how Honneth interprets the problems of Hegel's original project (3). Even though briefly, I conclude suggesting that, in the context of Honnethian project of updating Hegel's thought, it is possible to rereading three controversial concepts of the Hegelian theoretic framework: spirit, teleology and logic. In this way, I try to explicit a new interpretative nexus to Hegel's original idea, reread over current conceptual standars, as well as to pointing to possible new avenues for Honneth's project.
\end{abstract}

Keywords: Recognition, Ethical Life, Philosophy of Right, Freedom, Hegel, Honneth.

\footnotetext{
${ }^{1}$ Doutor em Filosofia pela Universidade de Frankfurt. Email: filipe.campello@ufpe.br .
} 
Tendo recebido uma ampla atenção no debate filosófico nas últimas décadas, uma das principais contribuições de Axel Honneth consiste em uma ambiciosa retomada do projeto original de Hegel no âmbito da filosofia política e teorias da justiça. Em linhas gerais, o projeto de Honneth situa-se num quadro em que se delineia a tentativa de atualização da problemática hegeliana em um registro pós-metafísico, no qual o conteúdo do pensamento hegeliano é retomado, mas é posta em questão a forma com a qual ele se expõe e se fundamenta, com vistas a evitar o que Honneth entende por "um retrocesso brutal de nossos padrões pós-metafísicos de racionalidade" (HONNETH, 2007, p. 50) ${ }^{2}$. Tal proposta de revestimento pós-metafísico da filosofia hegeliana é em grande parte inspirada pelo marco interpretativo de Jürgen Habermas, cuja proposta será guiada pelo processo de intersubjetivação da razão, inscrita agora num quadro comunicativo. É a partir da transformação linguístico-comunicativa da teoria idealista da intersubjetividade, protagonizada por Habermas, que uma concepção de racionalidade passa a vigorar nas próprias trocas comunicativas orientadas para o entendimento, onde o processo de validação das normas é estabelecido conforme a um espaço de razões intersubjetivamente mediado.

A teoria do reconhecimento de Axel Honneth irá se posicionar diante desse modelo de delineamento habermasiano, fortalecendo o caráter conflituoso das relações intersubjetivas, guiado não mais por um modelo da racionalidade comunicativa, mas por uma lógica que subjaz aos conflitos sociais. É com a publicação de sua tese de doutorado, sob o título de Kritik der Macht - Reflexionsstufen einer kritischen Gesellschaftstheorie (Crítica do Poder Estágios de reflexão de uma teoria social crítica), que Honneth demarca sua posição ao que entende como caráter insatisfatório das propostas anteriores da teoria crítica, cuja crítica é guiada pelo que o autor apresenta como "déficit sociológico" da teoria crítica ${ }^{3}$. A partir desta discussão marcadamente ex negativo, Honneth abre espaço para a elaboração de uma lógica moral dos conflitos sociais, o que, segundo a crítica honnethiana (1997), teria se mostrado insuficiente nas análises propostas pela teoria crítica até então. O objetivo desta interpretação é o de compreender o sistema social como resultado de uma lógica dos conflitos sociais marcados por uma tipologia de reinvindicações de reconhecimento intersubjetivo, retomando, na visão do autor, o fio condutor da tradição da teoria crítica. Este projeto é levado a cabo em Luta por Reconhecimento, resultado de sua tese de livre-docência escrita em Frankfurt na

\footnotetext{
${ }^{2}$ Quando não for indicado o autor, as citações referem-se aos escritos de Honneth, cujas referências encontramse na bibliografia.

${ }^{3}$ Honneth, 1985.
} 
posição de assistente de Habermas, onde Honneth apresenta o delineamento de seu próprio projeto de avanço diante dos problemas levantados em Crítica do Poder.

No que se segue, tentarei reconstruir as principais características da leitura de Hegel proposta por Honneth ${ }^{4}$. Com esse intuito, após expor a recepção da filosofia hegeliana para a elaboração da teoria do reconhecimento de Honneth em sua principal obra - Luta por reconhecimento - (1), discuto como Honneth leva a cabo seu projeto de atualização da teoria hegeliana da eticidade a partir da releitura de sua Filosofia do Direito (2). Numa terceira parte, será apresentada a interpretação de Honneth em torno dos problemas do projeto original de Hegel (3). Ainda que brevemente, concluo sugerindo que, no marco de projeto honnethiano de atualização do pensamento de Hegel, deixa-se entrever a possibilidade de releitura de três conceitos controversos do referencial teórico hegeliano: espírito, teleologia e lógica. Desse modo, tentarei explicitar novos nexos interpretativos em torno da ideia original de Hegel, relida a partir de atuais padrões conceituais, ao tempo em que são apontadas possibilidades de ampliação do projeto de Honneth.

1. A atualização do conceito hegeliano de reconhecimento e a proposta de um modelo pós-tradicional de eticidade

Para o marco teórico de sua abordagem, Honneth encontra nos escritos hegelianos do período de Jena os vestígios de uma teoria social embasada no conceito de reconhecimento. Notadamente na assim chamada Realphilosophie e no Sistema de Eticidade, Honneth propõe que o reconhecimento exerce uma função geradora da sociedade e permite conceituar o desenvolvimento da individualização associada à interação com a comunidade. É desse modo que, já no início de Luta por Reconhecimento, Honneth enquadra a filosofia política de Hegel como resposta à proposta da filosofia social moderna de reduzir a política à imposição de poder. Se o jovem Hegel, por um lado, recorre ao modelo hobbesiano da luta inter-humana para desenvolver sua teoria, para ele, por outro lado, o direito moderno teria se mantido preso a premissas atomistas, concebendo a "comunidade de homens" como "muitos associados", isto é, "a concatenação de sujeitos isolados, mas não segundo o modelo de uma unidade ética

\footnotetext{
${ }^{4}$ Este artigo retoma alguns argumentos que apresentei em um dos capítulos da dissertação de mestrado, ainda inédita, defendida em 2008 no Programa de Pós-Graduação em Filosofia da PUC-RS. 
de todos" (2003, p. 39-40). Honneth reconstrói o delineamento que Hegel encontrará em Fichte para compor o modelo de uma teoria do reconhecimento, ao tempo em que Hegel concede-lhe uma dinamização teórica sob a ênfase do conflito como elemento estruturante da relação. As relações éticas de uma sociedade representam as formas de uma intersubjetividade prática na qual o vínculo complementário entre os sujeitos e, com isso, a comunidade de indivíduos em relação é assegurada por um movimento de reconhecimento. $\mathrm{O}$ conflito por reconhecimento compreende o momento da negação - na qual o indivíduo coloca-se como parte de um todo - que leva à afirmação da identidade do sujeito. O conflito, assim, representa não o resultado, mas a experiência originária de subjetivação e que se mantém ao longo do processo de afirmação da identidade individual.

A formação do Eu prático está ligada à pressuposição do reconhecimento recíproco entre dois sujeitos: só quando dois indivíduos se veem confirmados em sua autonomia por seu respectivo defronte, eles podem chegar de maneira complementária a uma compreensão de si mesmos como um Eu autonomamente agente e individuado. (2003, pp. 119 e 120).

No entanto, aliando-se à interpretação de Habermas ${ }^{5}$, Honneth entende que Hegel, ao desenvolver seus textos posteriores, começando pela Filosofia do Espírito de 1803 e 1804, teria iniciado a subordinar a estrutura intersubjetiva do reconhecimento ao movimento especulativo e autogerador do espírito (Geist). Nessa leitura, "a eticidade se tornou uma forma do espírito que se autodesenvolve monologicamente e que não mais constitui uma forma de intersubjetividade" (2003, p. 86):

A guinada consequente para um conceito de eticidade próprio de uma teoria do reconhecimento, Hegel não o efetuou; no final, o programa da filosofia da consciência obteve tanto predomínio sobre as intuições da teoria do reconhecimento que, na última etapa do processo de formação, até mesmo seu conteúdo material acabou sendo pensado inteiramente conforme o modelo de uma autorrelação do espírito. (2003, p. 113)

Honneth propõe-se a levar a cabo dois aspectos centrais que, pela razão acima apontada, teriam permanecido em aberto no desenvolvimento dos escritos de Jena, a saber, o destino da vontade singular e a perspectiva concernente à concepção de comunidade genuinamente livre. Assim como em Habermas, a leitura honnethiana vê um desdobramento

\footnotetext{
${ }^{5}$ Habermas, 1968.
} 
circunscrito aos parâmetros da filosofia da consciência: "Para a solução dos dois problemas teria sido necessária a pressuposição de um conceito intersubjetivista de 'eticidade', do qual Hegel já não pode mais dispor, depois de quase consumada a passagem para a filosofia da consciência” (2003, p. 113). Hegel teria, então, deixado incompleto o desenvolvimento de uma teoria da intersubjetividade, pois "a sacrificou ao objetivo de erigir um sistema próprio à filosofia da consciência" (2003, p. 117). O lugar encontrado pela luta por reconhecimento no programa original dos escritos de Jena perde importância na proposta da Fenomenologia do Espírito, evidenciando-se a distância tomada diante de leituras francesas adeptas do viés kojeviano: ${ }^{6}$

A Fenomenologia do Espírito deixa para a luta do reconhecimento, que até então foi a força motriz que havia impulsionado o processo de sociabilização do espírito através de todas as etapas, tão-somente a função única de formar a autoconsciência (2003, p. 113-114)

Honneth entende que a Fenomenologia, apesar de ser "superior do ponto de vista do método, teve um efeito de um corte profundo na trajetória do pensamento de Hegel" (2003, p. 114). Em observância aos posteriores escritos de Hegel, Honneth conclui:

[...] Nem o conceito intersubjetivista de identidade humana, nem a distinção de diversos media de reconhecimento, nem a diferenciação correspondente de relações de reconhecimento gradualmente escalonadas, nem muito menos a ideia de um papel historicamente produtivo da luta moral voltam a assumir uma função sistemática na filosofia política de Hegel (2003, p. 114). ${ }^{7}$

Desse modo, tanto na leitura honnethiana de Luta por Reconhecimento como na de Habermas, os problemas da proposta original de Hegel referem-se ao problema da

\footnotetext{
${ }^{6}$ Outros textos também são críticos da interpretação de Kojéve. Kelly (1996), por exemplo, entende que essa leitura tende a distorcer a dialética do senhor e do escravo na estrutura do sistema hegeliano. Segundo o autor, há duas dificuldades na leitura a partir de Kóveje. Primeiramente, uma análise mais consistente de subjetividade teria sido negligenciada. Em segundo lugar, a relação senhor-escravo não deveria se aplicar à análise do progresso da história humana. Com isso, a crítica de Kelly a Kojéve é que ele trata a relação senhor-escravo somente como um confronto de esfera exterior (fundamentalmente a esfera política), enquanto que em Hegel há ainda o aspecto interior, composto pela abordagem lógico-epistemológica. Se para Kojéve, numa vertente marxista, as formas de servidão referem-se antes de tudo às relações de produção, Hegel teria relacionado a relação senhor-escravo também a um sentido epistemológico, em um conflito entre dimensão subjetiva e intersubjetiva. A ênfase numa perspectiva epistemológica, no quadro de validação intersubjetiva das normas, é proposta por Pinkard (1994).

${ }^{7}$ Mais recentemente, Honneth (2010) retoma a leitura da Fenomenologia, relacionado a dialética hegeliano do desejo com a teoria psicanalítica de Winnicott.
} 
substancialização da eticidade, ligados ao recuo à filosofia da consciência e, com ela, ao modelo de uma autorrelação do espírito ${ }^{8}$. Honneth entende que o processo de formação da subjetividade é inicialmente descrita por Hegel nos moldes de uma teoria da intersubjetividade inscrita nas relações comunicativas, renovando, assim, a doutrina hobbesiana do estado de natureza e sua relação com o caráter do conflito. No entanto,

essa construção se encontra ainda sob a pressuposição idealista de que o processo conflituoso a ser investigado é determinado por uma marcha objetiva da razão, que ou desdobra, aristotelicamente, a natureza comunitária do homem ou, nos termos da filosofia da consciência, a autorrelação do espírito. (2003, p. 118)

A partir desta interpretação, Hegel e Honneth, apesar do recurso ao conceito de reconhecimento ser em grande parte semelhante, partem de premissas distintas. Enquanto no sistema hegeliano o reconhecimento está vinculado à estrutura lógica de caráter especulativo, a lógica que Honneth encontra na estrutura do reconhecimento passa a estar ligada a uma gramática moral, segundo a qual os indivíduos experimentam a afirmação de sua identidade mediante relações de reconhecimento recíproco, em vista a um nível cada vez mais consolidado de individuação e autonomia. A leitura de Honneth, nesse caso, é marcadamente voltada à explicitação do nexo existente entre as formas de reconhecimento e a "lógica de um processo de formação mediado pelas etapas de uma luta moral” (2003, p. 121). Nesse sentido,

no curso da formação de sua identidade e a cada etapa alcançada da comunitarização, os sujeitos são compelidos, de certa maneira transcendentalmente, a entrar num conflito intersubjetivo, cujo resultado é o reconhecimento de sua pretensão de autonomia, até então ainda não confirmada socialmente (2003, p. 122-123).

No entanto, à diferença das críticas que se atêm à constatação da perda da intersubjetividade em Hegel, Honneth também extrai do pensamento hegeliano as intuições de uma teoria do reconhecimento, complementando a teoria habermasiana da intersubjetividade comunicativa com a luta e o conflito social. O conflito é visto como dimensão basilar das relações intersubjetivas, sendo demarcada, assim, uma estrutura relacional com contornos teóricos hegelianos. A ideia básica, aqui, é a de que o fator motivador dos conflitos sociais reside na ausência ou insuficiência de relações de

\footnotetext{
${ }^{8}$ Honneth, 2003; Habermas, 1987, 2000, 2004.
} 
reconhecimento recíproco. Esta aposta conduz o autor a analisar a concepção originária de Hegel da experiência do reconhecimento para melhor entender os conflitos e sintomas resultantes, por um lado, de sua ausência, e, por outro, das relações deficientes de reconhecimento, para, com isso, sugerir os elementos necessários para evitá-los.

Para este empreendimento, Honneth discute se a sequência de etapas propostas por Hegel resiste a considerações empíricas e se elas correspondem a formas de desrespeito social. Esta estratégia propõe-se a encontrar comprovações históricas e sociológicas para a ideia de que "essas formas de desrespeito social foram de fato fonte motivacional de confrontos sociais" (2003, p. 122). "A resposta a essas questões", conclui o autor, "conflui em seu todo à solução da tarefa de apresentar, pelo menos a traços largos, a lógica moral dos conflitos sociais"9 (2003, p. 122).

Na leitura honnethiana, a proposta de Hegel "permanece ligada à pressuposição da metafísica, na medida em que elas se devem meramente a uma transferência de relações construídas de maneira puramente conceitual para a realidade empírica" (2003, p. 121). O principal obstáculo para um projeto de atualização do conteúdo sistemático hegeliano estaria atrelado às "dificuldades que resultam do fato de sua linha de raciocínio central estar presa a premissas metafísicas que já não podem, sem mais, compatibilizar com as condições teóricas do pensamento atual" (2003, p. 117). A virada diante da proposta metafísica de Hegel pode ser assim expressa:

\begin{abstract}
Antes que se possa retomar hoje essa tipologia no sentido de uma reconstrução atualizadora, é necessária uma fenomenologia empiricamente controlada de formas de reconhecimento, mediante a qual a proposta de Hegel pode ser examinada e, se for o caso, corrigida. (2003, p. 121)
\end{abstract}

Dito de outro modo, Honneth pretende corroborar as intuições de Hegel diante da

\footnotetext{
${ }^{9}$ Desse modo, Honneth não retoma Hegel com o objetivo de elaborar uma teoria normativa das instituições (Siep, 2007), tampouco no sentido de propor uma concepção de moral ampliada no plano da teoria da subjetividade (Wildt, 1982). Apesar de partilhar com Siep a ideia de que "a doutrina do reconhecimento de Hegel pode ser compreendida no sentido de uma teoria da condição necessária da socialização humana" (Honneth, 2003, p. 119, nota), Honneth considera equivocada a intenção de extrair dessa proposta um critério normativo para julgar as instituições, "visto que não possuímos em princípio nenhum saber completo a respeito de que forma institucional pode assumir o cumprimento de determinadas e necessárias operações de reconhecimento" (Honneth, 2003, p. 119). Diante da proposta de Wildt (1982) de perseguir uma concepção de moral ampliada no plano da teoria da subjetividade, na perspectiva mais próxima de uma psicologia filosófica, Honneth objetiva extrair desses escritos um esboço de uma lógica dos conflitos sociais, dirigindo-se na direção de uma "sociologização" do modelo conceitual hegeliano.
} 
verificação empírica, mostrando que a intuição hegeliana do reconhecimento é profícua para uma teoria contemporânea do reconhecimento, não por estar apoiada numa estrutura especulativa que o fundamenta, mas porque, posto à prova mediante o diálogo empírico, ele se apresenta como uma resposta plausível para problemas constatados empiricamente. Desse modo, a releitura de Hegel proposta por Honneth consiste em levar a cabo a intuição original hegeliana, apoiando-a não mais em pressupostos metafísicos. Como é possível ler Hegel deste modo? A resposta pode ser encontrada na explicitação que Honneth (2003) oferece de sua metodologia.

Porém, uma abordagem que pretenda adotar um modelo de Hegel como estímulo para uma teoria social de teor normativo não pode se dar por satisfeita com esse fundamento meramente especulativo; daí ser preciso primeiramente uma reconstrução de sua tese inicial à luz de uma psicologia social empiricamente sustentada. (HONNETH, 2003, p. 121).

Seguindo este raciocínio, Honneth, ao dialogar com outros campos como a sociologia, a psicologia social e a psicanálise, procura fornecer maior consistência à proposta hegeliana. O referencial lógico, ou o que Honneth denomina de "gramática", passa a ser mediado pela pesquisa empírica, abandonando uma estrutura apriorística. É com esse intuito que Honneth encontra um respaldo empírico da proposta hegeliana na psicologia social de George Herbert Mead, "visto que seus escritos permitem traduzir a teoria hegeliana da intersubjetividade em uma linguagem teórica pós-metafísica" $\left(2003\right.$, p. 123) ${ }^{10}$. Com isso, para o seu projeto de atualização de Hegel orientada para a estruturação de um modelo pós-tradicional de eticidade, Honneth encontra em Mead "uma ponte entre a ideia original de Hegel e nossa situação intelectual" (2003, p. 123) ${ }^{11}$. Trata-se de conceder ao modelo hegeliano uma inflexão empírica que o torne mais sólido, plausível para um projeto crítico que atenda aos critérios de plausibilidade do pensamento contemporâneo. Em outras palavras, a proposta de Honneth consiste em encontrar em Hegel parâmetros para a elaboração de uma teoria social, mas recusa as premissas metafísicas do sistema hegeliano, substituindo-o por uma

\footnotetext{
${ }^{10} \mathrm{E}$, mais adiante: "A ideia de uma eticidade pós-tradicional, democrática, que se delineia como consequência dessa argumentação, foi desdobrada pela primeira vez pelo jovem Hegel e desenvolvida mais tarde por Mead sob premissas pós-metafísicas." (2003, p. 275). A discussão sobre os pormenores da inflexão empírica concedida por Honneth à abordagem hegeliana extrapolaria o objetivo específico de nossa argumentação.

${ }^{11}$ Mais recentemente, Honneth revê sua posição em relação à abordagem de Mead, distanciando-se desta abordagem desenvolvida em Luta por reconhecimento. Em um escrito posterior, Honneth defende que "o naturalismo da abordagem [de Mead, F.C] é, de certo modo, demasiado forte para ser possível conceber o reconhecimento como um comportamento habituado, que se realiza em um espaço de razões morais desenvolvidas historicamente" (Honneth, 1994, p. 313, tradução nossa).
} 
corroboração mediante o diálogo com as ciências empíricas. Honneth mostra que Hegel tem razão na sua proposta relacional da intersubjetividade, mas não porque isto reflete um fundamento lógico-ontológico, mas devido a uma reconstrução historicamente situada. A partir desta ponte empiricamente sustentada, Honneth sugere que

os diversos padrões de reconhecimento, que em Hegel foram distinguidos uns dos outros, podem ser compreendidos como as condições intersubjetivas sob as quais os sujeitos humanos chegam a novas formas de autorrelação positiva. (2003, p. 272)

Às esferas de reconhecimento são concedidos conteúdos morais fortalecidos pela corroboração empírica, como, por exemplo, a encontrada na teoria psicanalítica das relações de objetos - protagonizada pelo psicanalista inglês Donald Winnicott e relida por Jessica Benjamin - com a proposta de discutir o amor como expressão central de relações afetivas primárias. Com esta interlocução empírica, Honneth tem como objetivo corroborar a tese de uma teoria do reconhecimento que, neste caso, se refere à constituição da identidade na dimensão familiar. Em diálogo com a abordagem hegeliana, o autor frankfurtiano tenta encontrar uma gramática moral própria a cada uma das três esferas que Hegel, em sua Filosofia do Direito, propõe como integrantes do que ele denomina de eticidade (Sittlichkeit): a família, a sociedade civil e o Estado. Em linhas gerais, a tese honnethiana é a de que à família concerne experiência do amor, à sociedade civil compete a experiência da solidariedade, e, ao Estado, a do reconhecimento jurídico. A proposta de Honneth em Luta por reconhecimento pode ser assim resumida:

O nexo existente entre a experiência de reconhecimento e a relação consigo próprio resulta da estrutura intersubjetiva da identidade pessoal: os indivíduos se constituem como pessoas unicamente porque, da perspectiva dos outros que assentem ou encorajam, aprendem a se referir a si mesmos como seres a que cabem determinadas propriedades e capacidades. A extensão dessas propriedades e, por conseguinte, o grau de autorrealização positiva crescem com cada nova forma de reconhecimento, a qual o indivíduo pode referir a si mesmo como sujeito: desse modo, está inscrita na experiência do amor a possibilidade da autoconfiança, na experiência do reconhecimento jurídico, a do autorrespeito e, por fim, na experiência da solidariedade, a da autoestima. (HONNETH, 2003, p. 272) ${ }^{12}$.

12 E, numa outra passagem importante, Honneth complementa: "Só graças à aquisição cumulativa de autoconfiança, autorrespeito e autoestima, como garante sucessivamente as experiências das três formas de Pólemos, Brasília, vol. 3, n. 6, dez 2014 
Em torno da teoria honnethiana, interessa para a nossa exposição particularmente a proposta de interpretação da intuição original de Hegel. Honneth segue a premissa de preservar-se do risco de recair num modelo determinístico de relações sociais, privando-se da crítica a uma concepção a-histórica, ao mesmo tempo em que pretende fornecer parâmetros para um modelo de eticidade. Desse modo, Honneth dedica a parte final de Luta por Reconhecimento à proposta de um modelo formal de eticidade, encontrada nos parâmetros de uma teoria do reconhecimento orientada para uma "concepção formal de vida boa ou, mais precisamente, de eticidade" (2003, p. 271). "O conceito de eticidade", define Honneth, "refere-se agora ao todo das condições intersubjetivas das quais se pode demonstrar que servem à autorrealização individual na qualidade de pressupostos normativos" (2003, p. 271272). Mas o objetivo honnethiano não é o de propor formas particulares de vida boa circunscritas a contextos singulares. Por um lado, é proposta uma concepção de eticidade que seja delineada de maneira aberta, concedendo espaço para uma configuração particular variável de acordo com características espaço-temporais. Por outro, o autor pretende não recair em um formalismo abstrato, fornecendo ao modelo de eticidade um conteúdo significativamente consistente, qual seja, aquele verificado nas esferas de reconhecimento ${ }^{13}$. Desse modo, Honneth extrai de Kant a proposta de um quadro universal normativo (2003, p. 271), ao mesmo tempo em que encontra em Hegel as vantagens de um modelo intersubjetivo componente da eticidade. A concepção honnethiana de eticidade parte deste modelo proposto por Hegel, consolidando-o a partir de uma perspectiva mais ampla de revisão, pois,

de que maneira devem se constituir os pressupostos intersubjetivos da possibilitação da auto-realização se mostra sempre sob as condições históricas de um presente que abriu desde o início a perspectiva de um aperfeiçoamento normativo das relações de reconhecimento. (2003, p. 275)

Este modelo de eticidade pós-tradicional será levado adiante por Honneth a partir de um novo retorno a Hegel, na tentativa de reinterpretar a eticidade a partir da consolidação de

reconhecimento, uma pessoa é capaz de se conceber, de modo irrestrito, como um ser autônomo e individuado e de se identificar com seus objetivos e seus desejos. (2003, p. 266)

13 "De uma parte, os três distintos padrões de reconhecimento, que de agora em diante devem ser considerados as outras tantas condições de uma autorrealização bem-sucedida, são, segundo a sua definição, abstratos ou formais o suficiente para não despertar a suspeita de incorporarem determinados tipos de vida. De outra parte, a exposição dessas três condições é, sob o ponto de vista do conteúdo, rica o suficiente para enunciar mais a respeito das estruturas universais de uma vida bem-sucedida do que está contido na mera referência à autodeterminação.” (2003, p. 274) 
esferas de reconhecimento recíproco que assegurem um modelo comunicativo de liberdade.

\section{Patologias sociais da liberdade: a atualização honnethiana da Filosofia do Direito de Hegel}

No desenvolvimento de sua teoria, Honneth irá encontrar novas intuições na abordagem hegeliana, recorrendo agora a um escrito maduro de Hegel: a Filosofia do Direito $^{14}$. A releitura desta obra atende aos propósitos da elaboração de uma teoria da eticidade como Honneth iniciara a elaborar anteriormente em Luta por Reconhecimento, encontrando na Filosofia do Direito o desenvolvimento de uma teoria da eticidade nos padrões intersubjetivos de relações de reconhecimento.

Inicialmente, surpreende o fato de Honneth voltar sua atenção para um escrito do Hegel maduro, se, em Luta por Reconhecimento, as suas principais críticas dirigem-se às dificuldades do desenvolvimento do sistema hegeliano, quando, como vimos, ter-se-ia perdido o caráter preponderante da intersubjetividade presente nos escritos anteriores à Fenomenologia do Espírito. Se os motivos que levam Honneth a se deter neste escritos referem-se ao problema do desenvolvimento do conceito de espírito (Geist), também a proposta honnethiana de atualização da Filosofia do Direito de Hegel será desprendida do seu caráter sistemático, como veremos no que se segue.

Honneth nomeia duas razões que teriam provocado a perda de interesse pela Filosofia do Direito hegeliana. A primeira delas refere-se à crítica ao conceito substancialista de Estado, em que a objeção contra a perda da individualidade impedia de encontrar ali a plausibilidade de uma teoria normativa. A segunda reserva refere-se ao vínculo com a Lógica de Hegel. Em seu projeto de atualização, Honneth procura reconstruir a estrutura da Filosofia da Direito, evidenciando o nexo entre as esferas da eticidade e a consistência da argumentação hegeliana, "sem que a Lógica exerça uma função de suporte" (2007, p. 118) ${ }^{15}$. Em oposição às interpretações imanentes do sistema, o autor procura evidenciar que a

\footnotetext{
${ }^{14}$ Honneth, 2007.

15 “Os passos da fundamentação desenvolvidos por Hegel, objeta-se, só podem ser adequadamente reconstruídos e avaliados se forem referidos às partes correspondentes de sua Lógica, mas que entretanto se tornou completamente incompreensível em razão de seu conceito ontológico de espírito”. (Honneth, 2007, p. 49)
} 
Filosofia do Direito de Hegel, "mesmo independentemente, ou melhor, talvez exatamente por se colocar independentemente de toda reserva argumentativa de sua lógica, possui um grande poder de convencimento" (2007, p. 105). Ao mesmo tempo, Honneth não nega que as categorias da Filosofia do Direito encontram conceitos análogos na Lógica. Como ele afirma, “os próprios conceitos lógicos chaves, que se devem à lógica do ser, da essência e do conceito, se colocam como pano de fundo e dão lugar às categorias com as quais Hegel teria querido esclarecer seus esforços aos leitores e leitoras menos familiarizados” (2007, p. 105). E conclui: "por isso, parece aconselhável tratar o texto antes como um tipo de fonte de brilhantes ideias individuais, em vez de aspirar a uma tentativa frustrada de reconstrução da teoria integral enquanto tal" (2007, p. 49).

Honneth apresenta duas propostas de atualização: a direta e a indireta. Enquanto a primeira propõe-se a atualizar o texto segundo seus próprios padrões metódicos, a segunda consiste em reconstruir "de forma produtiva o propósito e a estrutura básica do texto" (2007, p. 50). Sobre a primeira proposta de atualização, a leitura direta, a justificativa de Honneth é que "corre o risco de salvar a substância da filosofia do direito hegeliana ao preço de um retrocesso brutal de nossos padrões pós-metafísicos de racionalidade” (2007, p. 50). A segunda proposta, por sua vez, "corre sempre o perigo de sacrificar a própria substância da obra com o objetivo de uma arrumação entusiasmada do texto" (2007, p. 50). Diante das reservas da leitura direta, que caracterizou a perda de interesse pela obra, Honneth opta pela segunda leitura indireta, considerando o texto como "fonte de brilhantes ideias individuais". Desse modo, ele recorre a uma leitura que retome a plausibilidade das intuições de Hegel, ao mesmo tempo em que esta leitura posiciona-se diante das críticas expostas anteriormente à teoria hegeliana, cujas objeções ao conceito substancialista de Estado e as dificuldades com a estrutura lógica teriam provocado a perda de interesse na Filosofia do Direito. Com isso, Honneth tenta mostrar que é possível extrair da Filosofia do Direito o quadro normativo para a efetivação do reconhecimento recíproco, cujo sentido é revisitado a partir do delineamento de uma teoria da eticidade, delineando-se, assim, um modelo normativo que forneça as condições de exequibilidade das relações de reconhecimento sugeridas por Hegel em escritos anteriores.

No desenvolvimento de sua exposição, HONNETH (2007, p. 54 ss.) nomeia quatro motivos que levaram Hegel a fundamentar o direito de forma diversa de Fichte e Kant, que podem ser assim resumidos: 
1. Pelo fato dos sujeitos já se encontrarem ligados constantemente em relações intersubjetivas, não se pode buscar uma fundamentação da justiça num princípio atomista segundo o qual a liberdade individual não seria influenciada pelos outros;

2. Efetuar o projeto dos princípios da justiça como "justificação daquelas condições sociais segundo as quais os sujeitos podem ver reciprocamente na liberdade do outro um pressuposto de sua autorrealização individual" (2007, p. 54);

3. A influência de cunho aristotélico nos escritos de juventude de Hegel manteve-se, segundo a qual os "princípios normativos de liberdade comunicativa na sociedade moderna não devem estar ancorados em preceitos externos voltados para o comportamento ou em meras leis de coerção, mas precisam estar atrelados ao exercício prático presente nos padrões habituais de ação e nos costumes" (2007, p. $54)$;

4. Uma tal cultura da "liberdade comunicativa", denominada eticidade, deveria comportar um espaço no qual os indivíduos pudessem perseguir seus próprios interesses ${ }^{16}$.

À diferença de seus antecessores, Hegel elabora o direito de forma a atender aos aspectos da efetivação da razão no âmbito do assim chamado "espírito objetivo", propondo a tarefa de expor as condições para a realização da liberdade individual. Com efeito, ela deve ser compreendida a partir das condições socialmente mediadas de efetivação da liberdade individual, configurando o nexo existente entre indivíduos autônomos. A tese de Honneth, que permeia a sua atualização da Filosofia do Direito de Hegel, é a de que as relações comunicativas possibilitam ao indivíduo a concepção de liberdade nos padrões do "serconsigo-mesmo-no-outro":

Hegel está interessado no que deve ser incorporado nessa realidade social, na existência, para que, com isso, a 'vontade livre' individual possa se desenvolver e se realizar, ainda que não diretamente, em uma instituição do direito caracterizada juridicamente; [...] as relações comunicativas, que possibilitam ao sujeito individual um "ser-consigo-

\footnotetext{
${ }^{16}$ Para Honneth, Hegel, ao formular um modelo comunicativo de liberdade, pretende superar um impasse inicial entre autonomia moral e autonomia jurídica. Esta concepção diverge da sugerida por Christoph Menke (1996), que encontra em Hegel uma tensão entre os dois modelos de autonomia. Sobre a relação entre direito e intersubjetividade no debate entre Fichte e Hegel, cf. o instrutivo estudo em Lima, 2015.
} 
mesmo-no-outro", devem pertencer essencialmente às condições de uma tal realização. (HONNETH, 2007, p. 64-65). ${ }^{17}$

Desse modo, cada estágio da Filosofia do Direito apresenta um direito peculiar ${ }^{18}$. Hegel ${ }^{19}$ retoma a definição kantiana, extraída da introdução da Doutrina do direito, de que "todo direito consiste em limitar a liberdade de todos os demais à condição de que possa coexistir com a minha, segundo uma lei universal" (KANT, Doutrina do Direito, Introdução APUD HEGEL, RP, §29, obs.). Hegel explica que essa definição contém apenas uma determinação negativa. Se, em Kant, o direito é entendido como restrição da liberdade, em Hegel, ele é condição de possibilidade para sua efetivação. Desse modo, sob o título de Filosofia do Direito, não se tem em vista "a tentativa de oferecer uma justificação normativa do papel social do direito caracterizado juridicamente", mas, antes, atribuir "um tipo de apresentação ética das condições sociais da autorrealização individual” (2007, p. 65). ${ }^{20}$ Nessa perspectiva, o conceito hegeliano de direito vai além do de Kant e Fichte, enquanto expressa os “pressupostos sociais que se mostraram necessários para a realização da 'vontade livre' do sujeito individual",21 (2007, p. 64).

O percurso argumentativo da Filosofia do Direito será pautado neste modelo de vontade livre, no intuito de apresentar as condições da efetivação da liberdade vinculadas à estrutura intersubjetiva da eticidade. As duas primeiras seções - direito abstrato e moralidade - são interpretadas como momentos antecedentes da consolidação do modelo intersubjetivo característico da eticidade. Já em Luta por Reconhecimento, Honneth havia definido a eticidade como "o todo das condições intersubjetivas das quais se pode demonstrar que

\footnotetext{
${ }^{17}$ Hegel remete ainda ao $\S 48$, onde é discutida a relação com os outros em referência à relação entre a existência corporal e a liberdade: "para os outros, eu sou essencialmente um ser livre em meu corpo, tal como o tenho imediatamente. [...] Sou livre para os outros só como livre na existência". Hegel acrescenta que esta questão é também discutida em sua Ciência da Lógica. Sobre este aspecto, Siep (2007) ressalta que "Hegel, por primeiro, na sua teoria do reconhecimento procurou colocar em relevo a dimensão corpóreo-emocional das relações intersubjetivas - como pressuposto da autoestima individual e de relação à questão da liberdade" (p. 50)

${ }^{18 “ " A}$ moralidade, a eticidade, o interesse do Estado, cada um é um direito próprio, porque cada uma dessas figuras é uma determinação e um ser-aí da liberdade" (Honneth, 2007, p. 69).

${ }^{19}$ As citações referentes à Filosofia do Direito de Hegel, indicada na bibliografia, serão abreviadas por "RP", seguidas do parágrafo.

${ }^{20}$ Honneth acrescenta que, "de acordo com o uso que Hegel, em sua Filosofia do direito, faz primeiramente do conceito de direito, não devem caber aos indivíduos os direitos universais vigentes, mas àquelas formas de existência sociais que se deixam mostrar como bens sociais básicos no interesse da realização da 'vontade livre"” (p. 66).

${ }^{21}$ Comparando a liberdade do direito e da autonomia, Honneth explica: "Com a absolutização de uma das duas representações da liberdade individual, seja em sua versão como pretensão de direito, seja em sua comparação com a autonomia moral [...], ocorrem rejeições patológicas na própria realidade social que são um indicador preciso e 'empírico' de que os limites do âmbito de validade legítimo foram transgredidos” (2007, p. 70).
} 
servem à autorrealização individual na qualidade de pressupostos normativos" (2003, p. 271272). É indicado, assim, que o direito se aplica, antes de tudo, ao que o autor entende por "formas de existência sociais" (sozialen Daseinsformen): Ao deslocar o eixo no qual gira o direito do indivíduo para as formas de existência sociais, Hegel embasa uma institucionalização da eticidade, no intuito de elaborar as condições nas quais seja possível a efetivação da liberdade, para a qual as instituições adquirem um papel de medium. Desse modo,

as condições sociais ou institucionais devem ser concebidas estritamente como o conjunto de uma ordem social justa que permite a cada sujeito individual participar em relações comunicativas que podem ser experienciadas como expressão da própria liberdade. (2007, p. 63)

Tais formas de existência sociais estruturam um modelo preocupado com as condições intersubjetivas da autonomia e liberdade, enquanto o direito refere-se a um quadro calcado em tais aspectos, indicando a ênfase na configuração social que permite a autorrealização individual. É nesse sentido que, na sua Filosofia do Direito, Hegel percebe a necessidade do caráter normativo para a efetivação da liberdade. Tendo em vista a relação entre subjetividade e intersubjetividade, Hegel teria que articular um modelo no qual tal relação pudesse ser atingida. Eis o objetivo que permeia a sua Filosofia do Direito, como apresenta Honneth:

na implementação de sua teoria da justiça, Hegel não se colocou apenas o objetivo de reconstruir corretamente aquelas esferas de ação intersubjetivas que, em vistas da estrutura comunicativa da liberdade, chegam a ser imprescindíveis para a realização da 'vontade livre'; além disso, ele quer atribuir àquelas concepções de liberdade seu lugar legítimo na ordem institucional de sociedades modernas. (2007, p. 68).

No percurso de sua argumentação, Honneth interpreta as duas seções da Filosofia do Direito anteriores à eticidade - direito abstrato e moralidade - como estágios incompletos da liberdade, mas que devem ser compreendidos na medida em que "eles contêm pressupostos constitutivos para a participação individual naquelas esferas comunicativas” (2007, p. 71). As duas primeiras seções indicariam os âmbitos nos quais Hegel desdobra os passos que proporcionam ao sujeito individual a autorrealização nas estruturas comunicativas da esfera 
ética, para a qual é preciso que se cumpram duas precondições: a de se compreenderem como portadores de direito e como pertencentes a uma ordem moral que lhes é oferecida.

Hegel parece querer dizer que apenas quando essas duas morais autorreferidas estão fundidas em um sujeito para a formação de uma identidade prática individual, ele pode então se realizar sem coerção no tecido institucional da eticidade moderna. (2007, p. 81)

A liberdade, aqui entendida, é sentida mediante as interações entre sujeitos, "pois somente na medida em que os sujeitos são capazes de participar desse tipo de relações sociais, eles podem, por conseguinte, realizar sem coerção sua liberdade no mundo exterior" (2007, p. 63). Nesse sentido, sob o título de "eticidade" é esboçado um modelo de relações institucionais de liberdade comunicativa, de modo que Hegel concebe "as relações comunicativas como um bem básico que tem de se colocar ao interesse de todos os homens com vistas à realização de sua liberdade" ${ }^{, 22}$ (2007, p. 63). Desse modo, a elaboração de um modelo normativo de eticidade deve ter em vista a articulação de uma teoria da justiça vinculada à ideia de possibilitação de bens básicos comunicativos, entendidos como relações de interação das quais os sujeitos podem dispor para a efetivação da liberdade. É a partir da argumentação dessas ideias que Hegel encontra uma legitimação para a relação ética de liberdade comunicativa, desenvolvida na terceira seção. Ao entender a liberdade como expressão do ser-consigo-mesmo-no-outro, Hegel cunha uma nova noção de relação entre justiça e indivíduo, concedendo-a um caráter intersubjetivo. Honneth argumenta:

Se a liberdade individual designa primeiramente e, sobretudo, o "serconsigo-mesmo-no-outro", então a justiça das sociedades modernas se mede pelo grau de sua capacidade de assegurar a todos os seus membros, em igual medida, as condições dessa experiência comunicativa e, portanto, de possibilitar a cada indivíduo a participação nas relações da interação não-desfigurada. (2007, p. 78-79)

\footnotetext{
${ }^{22}$ Como o próprio Honneth apresenta, a concepção hegeliana difere-se da de Rawls, pois não supõe que este bem básico seja repartido com justiça. Referindo-se a Hegel, Honneth afirma: "Parece que ele visa, na verdade, chegar à ideia de que a justiça das sociedades modernas depende da capacidade destas de possibilitar a todos os sujeitos igual participação no 'bem básico' de tais relações comunicativas” (2007, p. 63). Enquanto na definição de justiça de Hegel não está em jogo regras de distribuição no sentido rawlsiano, mas no máximo as condições gerais de tais práticas, Hegel "parece partir da hipótese de que as relações comunicativas incidem na classe daqueles bens que podem ser produzidos e conservados somente por meio de práticas comuns" (p. 79). Honneth conclui: "[...] Estou mais do que convencido de que, por meio de uma reelaboração ampliada dessa distinção entre Hegel e Rawls, chegamos exatamente ao ponto no qual se poderia conhecer, em traços largos, a concepção de justiça da Filosofia do direito" (2007, p. 79).
} 
Para Honneth, os argumentos de Hegel referem-se a uma justificação das condições necessárias de autorrealização individual e "o critério de uma tal justificação 'descritiva', que, entretanto, também já foi esclarecido suficientemente, é fornecido pelo princípio da insubstituibilidade quanto à possibilitação social de autodeterminação individual” (2007, p. 82). Nesse sentido,

se a realização da liberdade individual está ligada à condição da interação, uma vez que os sujeitos somente podem se experienciar como livres em suas limitações em face de um outro ser humano, então deve valer para toda a esfera da eticidade o fato de ter de residir nas práticas de interação intersubjetiva. (2007, p. 107)

As possibilidades de autorrealização individual, postas à disposição pela esfera da eticidade, são compostas pelas "formas de comunicação nas quais os sujeitos podem ver reciprocamente no outro uma condição de sua própria liberdade” (2007, p. 107), apontando para a ideia de que ações e práticas podem expressar o caráter de reconhecimento:

Reconhecer-se reciprocamente não significa somente relacionar-se com um outro numa atitude determinada de aceitação, mas implica também, e sobretudo, comportar-se diante do outro de um modo que se exija moralmente a forma correspondente de reconhecimento. $(2007$, p. 108)

Segundo esta proposta, a teoria da eticidade representa uma teoria normativa da modernidade, podendo ser encontrado na Filosofia do direito o lugar privilegiado de delineamento dos critérios para o estabelecimento do reconhecimento recíproco. Com o modelo de eticidade, revela-se "a exigência de que a ação intersubjetiva tem de poder expressar atitudes de reconhecimento" (2007, p. 110), de modo que as esferas da eticidade (família, sociedade civil e Estado) podem ser vistas como estruturas que possibilitam um crescente grau de satisfação de carências através de relações de reconhecimento, cujas características variam em cada uma delas. Desse modo, elas propõem uma hierarquização das esferas da eticidade a partir da concepção de níveis superiores de individuação. ${ }^{23}$ É nesse sentido que Honneth extrai de cada esfera da eticidade formas de comunicação peculiares que fornecem as condições para uma prova mútua de reconhecimento. Estas se restringem ao

\footnotetext{
23 "Em cada uma das três esferas o sujeito vê-se incluído simultaneamente com um aumento de sua própria personalidade, uma vez entendida esta como o grau de formação racional de uma individualidade natural que num primeiro momento ainda está desorganizada". (HONNETH, 2007, p. 122) 
caráter formal das relações de reconhecimento, restando o esclarecimento quanto aos conteúdos morais de cada uma delas.

A ampliação do conceito de liberdade na estrutura da eticidade irá revelar um sentido de liberdade incorporada pelos deveres, com a qual emerge a importância de ser apresentada uma "doutrina ética dos deveres" (RP $\$ 148)^{24}$. A conexão entre esses dois elementos deve evidenciar as "formas de interação social nas quais um sujeito somente pode alcançar a autorrealização se ele expressar, de um modo determinado, reconhecimento em face do outro" (2007, p. 110). Se, na interpretação hegeliana, em Kant o dever representa "um princípio vazio da subjetividade moral” (RP, §148), Hegel propõe que "as determinações éticas [devem] se apresentar como relações necessárias" (RP, §148). As normas não são sentidas como um dever limitador, mas como expressão da subjetividade em seu caráter objetivo. Em outras palavras, os deveres morais indicam o sentimento comum encontrado na relação intersubjetiva, onde os sujeitos se veem expressos não enquanto limitados, mas neles encontram pré-condições para sua autorrealização.

Hegel parece estar convencido de que só podemos falar de estruturas éticas, de relações éticas de vida, onde são dadas ao menos as seguintes condições: deve existir um padrão de práticas intersubjetivas que possibilite aos sujeitos se realizarem na medida em que se relacionam mutuamente, de modo a expressar reconhecimento por meio de sua consideração moral. (HONNETH, 2007, p. 112)

Em torno deste aspecto, Honneth entende o reconhecimento como a esfera de encontro entre aquilo que Harry Frankfurt denomina de first e second order volitions ${ }^{25}$. Frankfurt propõe, mediante essa distinção, caracterizar os âmbitos nos quais a liberdade está, por um lado, atrelada a nossos desejos, impulsos, e, por outro, referindo-se às condições externas que a possibilita. As first-orders-volitions podem ser entendidas como ações restritivas que geram a autorrealização da liberdade, como uma ação ilimitada e livre, como no caso da amizade e do amor ${ }^{26}$. Chega-se assim à estrutura do "ser-consigo-mesmo-nooutro", no qual uma nova concepção de vontade individual está correlacionada com a liberdade e a intersubjetividade.

\footnotetext{
24 "A esfera da eticidade deve abranger uma série de ações intersubjetivas nas quais os sujeitos podem encontrar tanto a realização individual quanto o reconhecimento recíproco" (2007, p. 110).

${ }^{25}$ Cf. Frankfurt, 1988, p. 11-25 apud Honneth, 2007, p. 59 ss.

${ }^{26} \mathrm{Cf}$. RP, §7, adendo.
} 
Somos efetivamente livres apenas quando sabemos formar nossas inclinações e carências de tal modo que estas sejam orientadas para o universal das interações sociais e cuja realização, por sua vez, possa ser experienciada como expressão da subjetividade irrestrita. (2007, p. 78)

$\mathrm{Na}$ argumentação de Honneth, o conceito de "espírito objetivo", relido sob o abandono de pressuposições metafísicas, conserva uma noção relevante: a de que a realidade social está ancorada em fundamentos racionais que, se violados, conduzem a patologias sociais. É nesse sentido que Hegel nomeia, dentro de um diagnóstico de época, patologias geradas pela insuficiência da liberdade nas duas primeiras esferas, tais como solidão (§136), vacuidade $(\S 141)$ ou abatimento $(\S 149)$. Para Honneth, tais patologias "podem ser colocadas conjuntamente sob o denominador comum de um 'sofrimento de indeterminação'[Leiden na Unbestimmtheit]" (2007, p. 104). A justificação de que as instituições sociais são racionais permite que Hegel legitime uma consonância entre elas e os indivíduos que as compõem. Tendo como pressuposto a racionalidade, Hegel sustenta que o comportamento da esfera social não é indiferente a uma configuração racional, de modo que uma desestruturação desse modelo pode ser corrigida mediante a referência a um modelo concebido racionalmente ${ }^{27}$. "A eticidade", conclui Honneth, "liberta-se de uma patologia social, na medida em que cria igualmente para todos os membros da sociedade as condições de uma realização da liberdade" $(2007$, p. 106)

\section{Novos parâmetros para uma teoria da eticidade}

\footnotetext{
${ }^{27}$ Neuhouser (2000) propõe-se a mostrar, em um instrutivo estudo sobre a filosofia prática de Hegel, que a estratégia argumentativa sobre o nexo hegeliano entre racionalidade e espírito objetivo contém uma plausibilidade maior do que a que normalmente se discute. A tese de Neuhouser (2000) é que as instituições são racionais porque promovem a liberdade social de seus membros. O autor mostra que Hegel encontra em Rousseau as bases para a articulação de um modelo de liberdade social, concedendo-o não só em sua configuração subjetiva, referente aos indivíduos, como também the concedendo um componente objetivo, compreendido nas instituições e nas leis racionais. As instituições são racionais enquanto comportam o caráter da subjetividade, que, por sua vez, nelas adquirem sua objetividade.

${ }^{28}$ Comentando a leitura de Honneth, Robert Pippin observa que "sofremos pela indeterminação contida numa mera noção de liberdade, enquanto a vacuidade da ideia de liberdade, tomada isoladamente, não traz consigo a determinação necessária para a autorrealização individual". (PIPPIN, 2010, p. 246). Pippin conclui: "Honneth evoca Hegel como tendo mostrado incisivamente a condição mais importante para a liberdade efetiva: a liberdade do outro, e, com ela, as condições sociais objetivas em que os sujeitos poderiam propriamente experienciar a liberdade do outro como condição da sua própria liberdade, e então atuar como agentes sociais e subjetivamente racionais" (2010, p. 246).
} 
$\mathrm{Na}$ intepretação de Honneth, como vimos, uma teoria da eticidade é relida segundo um modelo no qual não se sobressai nem o indivíduo isolado nem o conceito substancialista de Estado, mas o tecido social da eticidade. Com isso, as intuições que se mantiveram do jovem Hegel são relidas, notadamente a estrutura relacional da eticidade, pautada agora nos padrões comunicativos do "ser-consigo-mesmo-no-outro". É também a partir desse modelo interpretativo que, ao fim de sua proposta de atualização da Filosofia do Direito hegeliana, Honneth volta-se para o conceito hegeliano de Estado, alvo recorrente de críticas na literatura secundária $^{29}$. Em contraposição a estas leituras, o autor observa que alguns trechos destacam a possibilidade de efetivação da liberdade individual à medida que se consolida o tecido social da eticidade. Isto se deve ao conceito intersubjetivo de individuação, segundo o qual a esfera do Estado compreende um grau mais amplo de universalidade em que há uma complexificação do quadro de "relacionalidade". Neste âmbito das relações do Estado, e, um pouco antes, na passagem da sociedade civil ao Estado, é indicado o potencial do indivíduo em realizar "uma atividade universal" (RP, §255). Desse modo, o Estado deve oferecer as condições que permitam "ao homem ético, afora o seu fim privado, uma atividade universal" (RP, §255). Honneth comenta:

É a colaboração nesse 'universal', a participação ativa na reprodução da coletividade, que faz Hegel acreditar que esta permite um grau ainda maior de individualização: não em sua carência natural, nem em seu interesse individual, mas em seus talentos e habilidades formados racionalmente é que o sujeito se tornou, na esfera do Estado, membro da sociedade. (2007, p. 121-122)

No entanto, a conclusão da leitura de Honneth é a de que o referencial teórico hegeliano não deixa imune sua abordagem da eticidade, sem conseguir conjugar satisfatoriamente o papel do Estado e as configurações da liberdade individual e relações intersubjetivas. Hegel teria, então, apenas esboçado, mas sem desenvolver, a noção que Honneth denomina de "liberdade pública". Hegel, apesar da tendência republicana, não teria interpretado a esfera do Estado como "uma relação política de formação democrática da vontade" (2007, p. 144-145). Apesar de Hegel ter associado a legitimidade do Estado ao consentimento livre dos cidadãos, ele não lhes teria concedido o papel de proceder por meio

\footnotetext{
${ }^{29}$ Além da leitura de Habermas já mencionada anteriormente, uma das intepretações de referência nesta linha é a de Michael Theunissen (1982), que defende um déficit da relacionalidade no sistema hegeliano devido à subordinação do âmbito individual a uma estrutura substancialista.
} 
de "deliberação pública e da formação de opinião" (2007, p. 145), decidindo, assim, "quais devem ser os objetivos daquela ordem estatal" (2007, p. 145). Honneth conclui com a seguinte reflexão:

Apesar disso, um tal aperfeiçoamento democrático de sua doutrina da eticidade com objetivos de uma teoria da justiça, que Hegel perseguiu em toda a sua Filosofia do direito, teria se sustentado da melhor maneira possível: emoldurada no contexto de uma ordem moral capaz de assegurar a liberdade, e que forma em conjunto as três esferas éticas de reconhecimento, a tarefa da formação democrática da vontade na última esfera, que se constitui como a esfera propriamente política, teria sido encontrar a elaboração institucional dos espaços de liberdade. (2007, p. 145)

Desse modo, a concepção hegeliana de eticidade como espaço de interação comunicativa teria se limitado devido a uma concepção substancialista de Estado. Com o objetivo de extrair o que permite o avanço para uma teoria do reconhecimento, Honneth percebe a dificuldade de encontrar na proposta de Hegel o delineamento satisfatório de uma teoria da eticidade, e o motivo principal deve-se ao fato de que as formas de interação referem-se a um elemento externo às próprias interações intersubjetivas, restringindo o valor das esferas de comunicação. Em consonância com a crítica recorrente à perda da individualidade na concepção substancialista de Estado, Honneth ressalta que, em vários trechos do capítulo final da Filosofia do Direito, "manifesta-se um liberalismo autoritário que concede aos indivíduos todos os direitos fundamentais tradicionais, porém não thes dando chance alguma de configuração política" (2007, p. 144). Mesmo que seja plausível uma interpretação "republicana" em contraponto à liberal, é latente a dificuldade de encontrar, em ambas, a definição de uma estrutura deliberativa concedida às próprias trocas intersubjetivas, o que, como foi visto, reserva uma possibilidade de atualização da proposta original de Hegel. Ao considerar as interpretações republicana ou liberalista, a conclusão de Honneth é que:

Certamente que em nenhuma dessas duas alternativas de interpretação há a previsão de um lugar único no qual os "cidadãos do Estado" pudessem reunir-se para deliberar em conjunto sobre como deveriam ser qualificados os fins considerados "universal"; não se encontra na doutrina do Estado de Hegel o menor vestígio da ideia de uma esfera pública política, da concepção de uma formação democrática da vontade. (2007, p. 144) 
Ao fortalecer o papel da dimensão intersubjetiva na constituição da eticidade, Honneth mostra que as formas de interação contêm um potencial de formação cognitivo, associado ao desenvolvimento da capacidade de julgar moralmente. Desse modo, ele reforça a ideia de que o caráter de "segunda natureza", próprio da eticidade, já comporta a estabilidade necessária para os espaços comunicativos, vistos como esferas de realização da liberdade. O vínculo entre segunda natureza e costumes é latente neste modelo, o que reforçaria os sentidos dos costumes não como necessariamente juridicamente legitimados, mas como práticas estáveis compartilhadas intersubjetivamente (2007, p. 133 ss.). Nesta leitura, a esfera da eticidade poderia ser ampliada para além de uma estrutura normativa juridicamente autorizada, de modo que são revistas as condições de ação por parte do Estado, sem restringi-las às "instituições constituídas juridicamente" (2007, p. 135). Da mesma forma, é proposta uma maior flexibilização da eticidade, concedendo-lhe maior organicidade $^{30}$, de modo que o modelo de eticidade não pode ser representado:

nem como uma forma excessivamente fixa e imutável, pois com isso perderia toda a plasticidade que lhe é própria, nem concebida como uma massa meramente disponível ao estabelecimento do direito pelo Estado, uma vez que, desse modo, perderia em geral a característica de um "costume", a saber, de uma formação de hábitos que nunca poderá ser completamente regulada. (2007, p. 134)

É desse modo que Honneth resume o núcleo de sua crítica sob o título de "superinstitucionalização da eticidade". Dito brevemente, o autor propõe que esta dilatação da noção de eticidade, com uma espécie de enfraquecimento da estrutura normativa pautada no aparato institucional, proporciona, na primeira seção da eticidade, a inclusão de outras formas de interação. Na esfera da sociedade civil, por sua vez, permitiria a Hegel "tratar a 'sociedade civil' como uma esfera individual de reconhecimento na qual os sujeitos realizam seus fins privados graças a interações estratégicas" (2007, p. 142). Nesse sentido, a abordagem hegeliana não teria pensado adequadamente o Estado como uma esfera de reconhecimento recíproco, o que seria compatível com sua concepção de vida universal e de ações entrelaçadas "segundo leis e princípio pensados, isto é, universais" (RP, §258). Isso se

\footnotetext{
${ }^{30}$ Essa questão remete ao recente debate sobre a ideia de uma juridificação da democracia, em que são indicadas limitações do teor ético enquanto balizado estritamente pela esfera jurídica. Esta crítica aponta uma lacuna quando as noções de certo e errado relativo a conteúdos morais serão definidos basicamente pelo que é definido formalmente pela esfera jurídica, na qual as penalidades tendem a ocorrer somente quando este âmbito é infringido. Sobre essa questão na interpretação de honnethiana, cf. Honneth, 2011. Sobre o tema, cf. também Flickinger, 1986.
} 
deve ao enfraquecimento das estruturas de reconhecimento diante do tratamento substancialista que o Estado recebe. Desse modo, o principal problema da doutrina da eticidade hegeliana é que,

ainda que tudo nela esteja disposto de uma tal maneira que se constitua nas três esferas apenas um padrão de interação capaz de garantir a liberdade, essa intenção formal não pode ser realizada porque seu ponto de vista está voltado muito fortemente para as formas concretas de organização. (2007, p. 141)

Nesta interpretação, Hegel deveria ter diferenciado entre "uma análise normativa das sociedades modernas para identificar as condições historicamente produzidas da liberdade individual" (2007, p. 142) e uma "análise das instituições com que pode legitimar as formas de organização que se desenvolveram ancoradas no direito" (2007, p. 142). Se, por um lado, o Estado deve garantir a existência adequada e a devida manutenção das esferas distintas de reconhecimento, por outro lado, a insistência de Hegel na institucionalização positivada juridicamente não seria de todo necessária, uma vez que "as diferentes esferas da eticidade devem ser pensadas como relações sociais de interação nas quais todo sujeito deve poder participar igualmente por razões da liberdade" (2007, p. 134). Com isso, mais uma vez evidencia-se um projeto de ampliação da estrutura normativa para além daquela proporcionada por estruturas institucionalmente rígidas.

Ainda que visto numa ponderação provisória, gostaria de concluir sugerindo que, no marco de projeto honnethiano de atualização do pensamento de Hegel, conforme exposto, é possível entrever a releitura de três conceitos controversos do referencial teórico hegeliano: espírito, teleologia e lógica - que, no que se segue, podemos apenas indicar brevemente.

Primeiramente, a noção de espírito permitira a Hegel articular a constituição da subjetividade na sua relação com a historicidade e com a objetividade das formas sociais, ao tempo em que a objetividade adquirira a identificação com a subjetividade nela expressa. A revisão do conceito de espírito, reescrito agora segundo um padrão que se coloque como alternativo ao modelo de espírito autorreflexivo, concede-lhe um delineamento mais dinâmico e flexível, ampliando a configuração da eticidade. Desse modo, o conceito de espírito pode ser relido no sentido de desenvolver um modelo orgânico de eticidade, deslocando a ênfase de uma estrutura autorreflexiva para as trocas comunicativas da comunidade linguística. 
Com isso, o sentido teleológico revela-se na proposta de um direcionamento para formas cada vez mais consolidadas de relações de reconhecimento, conferindo ao modelo de eticidade um caráter evolutivo que se dirige a formas mais elaboradas de vida boa. $\mathrm{O}$ significado de teleologia, portanto, torna-se condicionado a formas particulares das relações de reconhecimento, a partir de um quadro construído histórico e socialmente. Uma concepção de espírito, de alguma forma, permanece, mas não teleologicamente incondicionada ${ }^{31}$, senão atrelada às práticas intersubjetivas que conferem dinamicidade e movimento às "formas de existência sociais".

A lógica, por sua vez, mostra-se não mais como apriorística, mas vinculada à gramática inscrita nas relações de reconhecimento, que proporcionam detectar os padrões que perpassam as lutas por reconhecimento. Honneth entende que aquelas relações de reconhecimento comportam uma forma universalmente válida, enquanto visam propor uma "gramática" que forneça um padrão processual, não mais no sentido de uma lógica apriorística, mas inscrito nas relações intersubjetivas. O sentido de universalidade permanece, enquanto por gramática se entende uma estrutura compartilhada por todos os membros da sociedade, aplicada, no caso da teoria do reconhecimento, a formas de reconhecimento e patologias geradas quando estas formas são deficientes ou inexistentes. Ao mesmo tempo, o formato que tais relações adquirem permanece variável. Com isso, Honneth pretende fornecer um modelo "pós-tradicional de eticidade" (2003, p. 276), que esteja ancorado na historicidade, aberto a mudanças, mas que não perca seu teor normativo. Os contornos de sua forma são delineados e dela fazem parte os conteúdos morais que requerem formas específicas de reconhecimento, mas o formato destas relações não é predeterminado. Ampliase, portanto, a possibilidade de revisão da estrutura ética, que, em Hegel, teria sido vinculada a uma lógica aprioristicamente determinada.

Nesse sentido, verifica-se que tanto na abordagem metafísica hegeliana quanto na teoria de Honneth é proposto o delineamento de uma lógica que subjaz às formas de configuração social. A diferença central entre as duas perspectivas é que, em Hegel, esse delineamento é traçado aprioristicamente, configurando um quadro apoiado numa fundamentação lógicoontológica que permite encontrar nela própria a estrutura especulativa do real. No caso de Honneth, este tipo de fundamentação não é mais válido, o que o leva a procurar uma gramática pós-metafísica, no quadro de um diálogo que propicie um tipo de embasamento

\footnotetext{
${ }^{31}$ Sobre o conceito de "teleologia do incondicionado" em Hegel, cf. Luft (2001). 
empiricamente sustentado. Honneth pretende fornecer aquilo que ele denomina de gramática moral dos conflitos sociais, mas propõe uma maior flexibilidade, sem instituir que tipos de práticas as formas de interação adquirem. Uma gramática, à semelhança do sentido wittgensteiniano, apresenta uma estrutura descritivo-normativa que em muito se assemelha a uma "lógica do real", no sentido hegeliano, retirando-lhe, no entanto, o seu caráter apriorístico. O diálogo honnethiano com as contribuições como as da psicanálise e da psicologia social indica uma preocupação semelhante à proposta hegeliana em tornar evidente um quadro estrutural para a análise da sociedade, mesmo que não mais com uma fundamentação última. Percebe-se que esta mudança de orientação, guiada agora pelo norte pós-metafísico, não implica uma necessária eliminação da referência a princípios reguladores, cujo significado permanece na concepção honnethiana de "gramática".

Uma atualização de Hegel, ainda que revise seus pressupostos metafísicos, possibilita a elucidação da consistência de seu pensamento e sua atualidade para o debate contemporâneo. Antes de se colocar como uma crítica externa ao sistema hegeliano, a abordagem de Honneth, ao desvincular-se de uma leitura autorreferencial do texto hegeliano, contribui significativamente para a retomada de Hegel no debate da filosofia política e teorias da justiça contemporânea, elucidando a fecundidade e atualidade de seu pensamento. Ao mesmo tempo, o retorno a Hegel pode indicar uma ampliação do propósito da teoria honnethiana, cuja articulação de um diálogo empírico e crítica a uma estrutura lógica apriorística possibilitaram a atualização da teoria hegeliana. O desenvolvimento desse modelo teórico pode conduzir ao desenvolvimento de uma gramática não só dos conflitos sociais, mas ampliada a uma teoria mais abrangente, vista não mais como apriorística, mas aberta à revisão mediante a interlocução com as ciências empíricas e alicerçada na historicidade. Ao ler Honneth, são fornecidos elementos teóricos para uma atualização crítica do pensamento de Hegel, assim como, inversamente, o retorno a Hegel pode contribuir para o desenvolvimento do marco teórico honnethiano, com vistas a abranger novos horizontes de pesquisa.

\section{Referências}

CAMPELLO, Filipe. Do reconhecimento à liberdade social: Sobre 'O direito da liberdade', de Axel Honneth. Cadernos de Ética e Filosofia Política (USP), v.2, p.186 - 197, 2014. 
FLICKINGER, Hans-Georg. O paradoxo do liberalismo político: A juridificação da democracia. FilosofiaPolítica. 3, 1986. p. 117-129.

HABERMAS, Jürgen. Arbeit und Interaktion. Bemerkungen zu Hegels Jenenser „Philosophie des Geistes“, In: . Technik und Wissenschaft als Ideologie. Frankfurt am Main: Suhrkamp, 1968.

. O Discurso Filosófico da Modernidade. São Paulo: Martins Fontes, 2000.

HEGEL. G.W.F. Grundlinien der Philosophie des Rechts. In: Werke in 20 Bände. Frankfurt am Main: Suhrkamp, 1970, Band VII.

HONNETH, Axel. Kritik der Macht: Reflexionsstufen einer kritischen Gesellschaftstheorie. Frankfurt: Suhrkamp, 1985.

. Der Grund der Anerkennung. Eine Erwiderung auf kritische Rückfragen. Posfácio, In:___ Kampf um Anerkennung. Zur moralischen Grammatik sozialer Konflikte: Mit einem neuen Nachwort. Frankfurt am Main: Suhrkamp, 1994.

. Luta por reconhecimento: a gramática dos conflitos sociais. São Paulo: 34, 2003.

. Sofrimento de indeterminação. São Paulo: Esfera Pública, 2007.

. Von der Begierde zur Anerkennung. In: . Das Ich im Wir. Berlin: Suhrkamp, 2010, p. 15-32.

. Das Recht der Freiheit. Grundriß einer demokratischen Sittlichkeit. Berlin: Suhrkamp, 2011.

KELLY, George Armstrong. Notes on Hegel's “Lordship and Bondage”. In: O’NEILL, John. Hegel's Dialectic of desire and recognition. New York: State University of New York, 1996.

LUFT, Eduardo. As sementes da dúvida: Investigação crítica dos fundamentos da filosofia hegeliana. São Paulo: Mandarim (Siciliano), 2001.

LIMA, Erick Calheiros de. Direito e intersubjetividade em Fichte e Hegel. Campinas: Editora Phi, 2014.

MENKE, Christoph. Tragödie im Sittlichen. Gerechtigkeit und Freiheit nach Hegel. Frankfurt am Main: Suhrkamp, 1996.

NEUHOUSER, Frederick. Foundations of Hegel's Social Theory. Actualizing Freedom. Cambridge, MA: Harvard University Press, 2002.

PINKARD, Terry. Hegel's phenomenology. The sociality of reason. Cambridge: Cambridge University Press, 1994.

PIPPIN, Robert. Hegel's practical philosophy. Rational agency as ethical life. Cambridge: Cambridge University Press, 2010. 
Filipe Campello

SIEP, Ludwig. Anerkennung als Prinzip der praktischen Philosophie. Untersuchungen zu Hegels Jenaer Philosophie des Geistes. Freiburg/München: Verlag Karl Alber, 1979.

WILDT, Andreas. Autonomie und Anerkennung: Hegelsmoralitätskritik im Lichte seiner Fichte-Rezeption. Stuttgart: Klett-Cotta Verlag, 1982. 